Article

\title{
Improved Field Electron Emission Properties of Phosphorus and Nitrogen Co-Doped Nanocrystalline Diamond Films
}

\author{
Fernando Lloret $1,2,3, * \mathbb{D}$, Kamatchi Jothiramalingam Sankaran ${ }^{1,2,{ }^{\dagger}}$, Josué Millan-Barba ${ }^{4}$, \\ Derese Desta ${ }^{1,2}$, Rozita Rouzbahani ${ }^{1,2}$, Paulius Pobedinskas ${ }^{1,2}\left(\mathbb{0}\right.$, Marina Gutierrez ${ }^{4}$, \\ Hans-Gerd Boyen ${ }^{1,2}$ and Ken Haenen ${ }^{1,2, *(1)}$ \\ 1 Institute for Materials Research (IMO), Hasselt University, 3590 Diepenbeek, Belgium; \\ Kjsankaran.immt.res.in (K.J.S.); Derese.desta@uhasselt.be (D.D.); Rozita.rouzbahani@uhasselt.be (R.R.); \\ Paulius.pobedinskas@uhasselt.be (P.P.); hansgerd.boyen@uhasselt.be (H.-G.B.) \\ 2 IMOMEC, IMEC vzw, 3590 Diepenbeek, Belgium \\ 3 Department Fisica Aplicada, Universidad de Cádiz, 11510 Puerto Real, Spain \\ 4 Department Ciencia de los Materiales e IM y QI, Universidad de Cádiz, 11510 Puerto Real, Spain; \\ josmilbar@gmail.com (J.M.-B.); marina.gutierrez@uca.es (M.G.) \\ * Correspondence: fernando.lloret@uca.es (F.L.); ken.haenen@uhasselt.be (K.H.) \\ + Current address: CSIR-Institute of Minerals and Materials Technology, Bhubaneswar-751013, India
}

Received: 30 April 2020; Accepted: 22 May 2020; Published: 27 May 2020

\begin{abstract}
Nanocrystalline diamond (NCD) field emitters have attracted significant interest for vacuum microelectronics applications. This work presents an approach to enhance the field electron emission (FEE) properties of NCD films by co-doping phosphorus $(\mathrm{P})$ and nitrogen $(\mathrm{N})$ using microwave plasma-enhanced chemical vapor deposition. While the methane $\left(\mathrm{CH}_{4}\right)$ and $\mathrm{P}$ concentrations are kept constant, the $\mathrm{N}_{2}$ concentration is varied from $0.2 \%$ to $2 \%$ and supplemented by $\mathrm{H}_{2}$. The composition of the gas mixture is tracked in situ by optical emission spectroscopy. Scanning electron microscopy, atomic force microscopy (AFM), transmission electron microscopy, and Raman spectroscopy are used to provide evidence of the changes in crystal morphology, surface roughness, microstructure, and crystalline quality of the different NCD samples. The FEE results display that the $2 \% \mathrm{~N}_{2}$ concentration sample had the best FEE properties, viz. the lowest turn-on field value of $14.3 \mathrm{~V} / \mu \mathrm{m}$ and the highest current value of $2.7 \mu \mathrm{A}$ at an applied field of $73.0 \mathrm{~V} / \mu \mathrm{m}$. Conductive AFM studies reveal that the $2 \% \mathrm{~N}_{2}$ concentration NCD sample showed more emission sites, both from the diamond grains and the grain boundaries surrounding them. While phosphorus doping increased the electrical conductivity of the diamond grains, the incorporation of $\mathrm{N}_{2}$ during growth facilitated the formation of nano-graphitic grain boundary phases that provide conducting pathways for the electrons, thereby improving the FEE properties for the $2 \% \mathrm{~N}_{2}$ concentrated NCD films.
\end{abstract}

Keywords: nanocrystalline diamond; field electron emission; phosphorus; nitrogen; conductive atomic force microscopy; transmission electron microscopy

\section{Introduction}

Diamond is a versatile material whose properties make it interesting for a wide range of applications, from abrasives to power electronics [1]. Among these applications, polycrystalline diamond-based field emitters have attracted significant interest in vacuum microelectronics due to their negative electron affinity for electron emission, strong bonding structure, 
extreme hardness to withstand ion bombardment, and good thermal and electrical conductivities to handle high currents $[2,3]$.

Chemical vapor deposition (CVD) is the most used technique for producing polycrystalline diamond. Using methane and hydrogen as gas precursors, it is possible to obtain diamond films with grain sizes ranging from tens of nanometers to hundreds of microns. Microcrystalline diamond (MCD) films possess micron-sized grains resembling monocrystalline diamond, implying a wide bandgap and hindering the field electron emission (FEE) behavior because of a shortage of electrons in the conduction band [4]. As grain boundaries are known to be more conductive due to the presence of $\mathrm{sp}^{2}$-bonded carbon, efforts must be directed to a reduction of the diamond grain size. Nitrogen addition in $\mathrm{CH}_{4} / \mathrm{H}_{2}$ plasma effectively reduces the size of the diamond grains from micron to nanosized, yielding nanocrystalline diamond (NCD) films. It also facilitates the formation of nanographitic phases in the grain boundaries, for which an improvement in the electrical conductivity and subsequent FEE properties have been demonstrated [5-8]. The grain boundary conduction mechanism has been proposed for the enhancement of FEE properties of these $\mathrm{N}$-doped NCD films $[9,10]$. Still, the nanosized diamond grains are insulating in nature, which limits conduction to the grain boundaries, thereby limiting the FEE properties of N-doped NCD films. On the other hand, it is known that $\mathrm{P}$ forms a donor in both single as well as polycrystalline diamond, with the $\mathrm{P}$ atom mostly incorporating in substitutional positions in the grains [11,12].

Here we present an approach to synthesize phosphorus and nitrogen co-doped NCD films, with the aim of improving the FEE properties of N-doped NCD films. With the target of obtaining a large proportion of conducting grain boundary phases (due to $\mathrm{N}$-doping) between conducting P-doped diamond grains, P and N co-doped NCD films were deposited on Si substrates by microwave plasma-enhanced chemical vapor deposition (MWPECVD), and the optimum growth conditions to enhance the FEE properties were determined. The composition of the gas mixture during growth was tracked in situ by optical emission spectroscopy (OES). The resulting NCD films were characterized by scanning electron microscopy (SEM), atomic force microscopy (AFM), Raman spectroscopy, transmission electron microscopy (TEM), and conductive AFM (C-AFM).

\section{Materials and Methods}

A total of five $10 \times 10 \mathrm{~mm}^{2} \mathrm{n}$-type mirror-polished (100)-oriented silicon substrates $(10-20 \mathrm{k} \Omega \cdot \mathrm{cm})$ were exposed to an $\mathrm{O}_{2}$ plasma for $1 \mathrm{~min}$ at $200 \mathrm{~W}$ and $50 \mathrm{sccm}$ total flux in order to prepare the surface for diamond seeding. Oxygen plasma was used to clean the surface of organic contamination and to improve the hydrophilicity of the surface. Substrates were then seeded by drop-casting with a water-based colloidal suspension of ultra-dispersed detonation nanodiamond of size 6-7 nm (NanoCarbon Institute Co., Ltd., Japan.) and subsequent spin-drying [13]. Growth was carried out in an MWPECVD ASTeX reactor. A mixture of $\mathrm{CH}_{4}, \mathrm{H}_{2}, \mathrm{~N}_{2}$, and $\mathrm{PH}_{3}$ gases was used with a total flux of $500 \mathrm{sccm}$. $\mathrm{CH}_{4}$ and $\mathrm{PH}_{3}$ were kept constant at $1 \%$ and $0.01 \%$, respectively, in all the deposition experiments, while the proportion of $\mathrm{N}_{2}$ was varied from $0.2 \%$ to $2 \%$ and complemented by $\mathrm{H}_{2}$. The working pressure and microwave power were set at 70 Torr and $2100 \mathrm{~W}$, respectively, leading to a temperature of the growth surface in the range of 760 to $800{ }^{\circ} \mathrm{C}$, which was measured by a single-color optical pyrometer with the emissivity set to 0.3. An AvaSpec-2048 spectrometer with a spectral resolution of $1 \mathrm{~nm}$ per pixel was used to track the composition of the plasma region in contact with the sample by OES. All the samples were grown for a thickness of $\sim 200 \mathrm{~nm}$. Table 1 summarizes the growth conditions used for each sample. 
Table 1. Growth conditions used during the microwave plasma-enhanced chemical vapor deposition (MWPECVD) deposition of the nanocrystalline diamond (NCD) layers, Ra determined by AFM and full width at half maximum (FWHM) of the dia peak, corresponding to the Raman spectrum.

\begin{tabular}{cccccccc}
\hline Power & Pressure & Temperature & $\mathbf{C H}_{\mathbf{4}}$ & $\mathbf{P H}_{\mathbf{3}}$ & $\mathbf{N}_{\mathbf{2}}$ & $\mathbf{R a}$ & FWHM “dia" \\
\hline $2100 \mathrm{~W}$ & 70 Torr & $760-800^{\circ} \mathrm{C}$ & $1 \%$ & $250 \mathrm{sccm}$ & $0.2 \%$ & $67 \mathrm{~nm}$ & $14.0 \mathrm{~cm}^{-1}$ \\
$2100 \mathrm{~W}$ & 70 Torr & $760-800^{\circ} \mathrm{C}$ & $1 \%$ & $250 \mathrm{sccm}$ & $0.35 \%$ & $40 \mathrm{~nm}$ & $15.7 \mathrm{~cm}^{-1}$ \\
$2100 \mathrm{~W}$ & 70 Torr & $760-800^{\circ} \mathrm{C}$ & $1 \%$ & $250 \mathrm{sccm}$ & $0.5 \%$ & $34 \mathrm{~nm}$ & $12.8 \mathrm{~cm}^{-1}$ \\
$2100 \mathrm{~W}$ & 70 Torr & $760-800^{\circ} \mathrm{C}$ & $1 \%$ & $250 \mathrm{sccm}$ & $1 \%$ & $32 \mathrm{~nm}$ & $20.3 \mathrm{~cm}^{-1}$ \\
$2100 \mathrm{~W}$ & 70 Torr & $760-800^{\circ} \mathrm{C}$ & $1 \%$ & $250 \mathrm{sccm}$ & $2 \%$ & $30 \mathrm{~nm}$ & $16.2 \mathrm{~cm}^{-1}$ \\
\hline
\end{tabular}

Grain morphology was studied by SEM using an FEI Quanta 200 FEG operated with $15 \mathrm{kV}$ accelerating voltage, while surface roughness was evaluated by AFM using a Bruker Multimode 8 in tapping mode. The crystalline quality of the films was examined using a Horiba Jobin Yvon T64000 Raman spectrometer equipped with a BXFM Olympus 9/128 microscope, in combination with a Horiba Jobin Yvon Symphony CCD detector and a $488 \mathrm{~nm}$ Lexell SHG laser. The deposited NCD layers were studied in planar-view preparation by TEM at $200 \mathrm{keV}$ accelerating voltage using a JEOL 2100 TEM. TEM samples were prepared by mechanical polishing and ion milling.

Room-temperature field electron emission (FEE) measurements of the NCD films were carried out by a diode-type apparatus inside a vacuum chamber at a pressure of $2 \times 10^{-8} \mathrm{mbar}$. An Mo rod of $3 \mathrm{~mm}$ diameter acted as an anode, and the NCD films were used as the cathode. A micrometer feed-through with $1 \mu \mathrm{m}$ resolution was used to control the anode-to-cathode distance. A Keithley 6517B electrometer (Keithley Instruments, Inc., Cleveland, OH, USA) was used to acquire the current-voltage $(I-V)$ characteristics. C-AFM (NX-10, Park Systems) measurements were carried out at a negative substrate bias voltage of $-5 \mathrm{~V}$ using an Au-coated silicon cantilever (NPG-10) from Bruker.

\section{Results and Discussion}

SEM observations were carried out in order to analyze the changes in the grain morphology of the NCD films. The SEM micrograph of the $0.2 \% \mathrm{~N}_{2}$ NCD sample (Figure 1a) showed a larger grain size of $1 \mu \mathrm{m}$ diameter for the biggest grains. Most of the grains looked (111)-faceted, with some not very evident re-nucleation in the edges. Figure $1 \mathrm{~b}$ shows the surface of the sample growth at $0.35 \% \mathrm{~N}_{2}$, where the effect of the increase of nitrogen on the grain morphology is clear. Grains were drastically reduced to nanometric scale, where the largest ones were only a few hundred nanometers in diameter. Facets were not as evident in this case. The grain size continued reducing, and the shape became so-called cauliflower-like when nitrogen content was increased. The NCD sample grown at $2 \% \mathrm{~N}_{2}$, shown in Figure 1e, clearly exhibited small grains with many different facets in a clear cauliflower morphology that predicted larger grain boundary regions. 

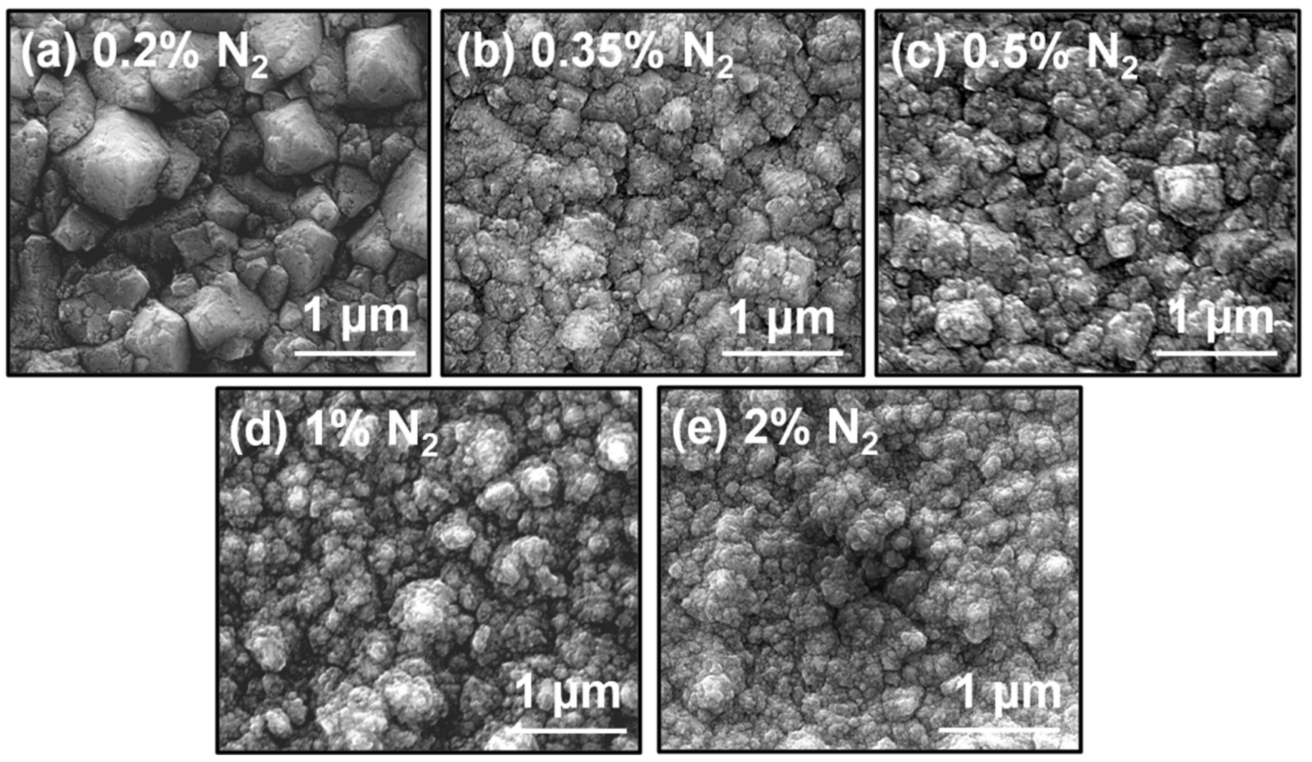

Figure 1. SEM micrographs of the samples grown with (a) $0.2 \% \mathrm{~N}_{2}$, (b) $0.35 \% \mathrm{~N}_{2}$, (c) $0.5 \% \mathrm{~N}_{2}$, (d) $1 \% \mathrm{~N}_{2}$ and (e) $2 \% \mathrm{~N}_{2}$.

Figure 2 shows AFM micrographs of each sample. The average roughness reduced with increasing nitrogen content, resulting in the $R a$ values of: $67,40,34,32$, and $30 \mathrm{~nm}$ for $0.2 \%, 0.35 \%, 0.5 \%, 1 \%$, and $2 \% \mathrm{~N}_{2}$ content, respectively. Thus, from $0.2 \%$ to $0.5 \%$, there was a huge reduction of roughness, indicating a big change in the morphology of the diamond grains. The surface remained smoother at higher nitrogen concentration, but variations were not as abrupt. These results were in good agreement with the SEM micrographs (cf. Figure 1).
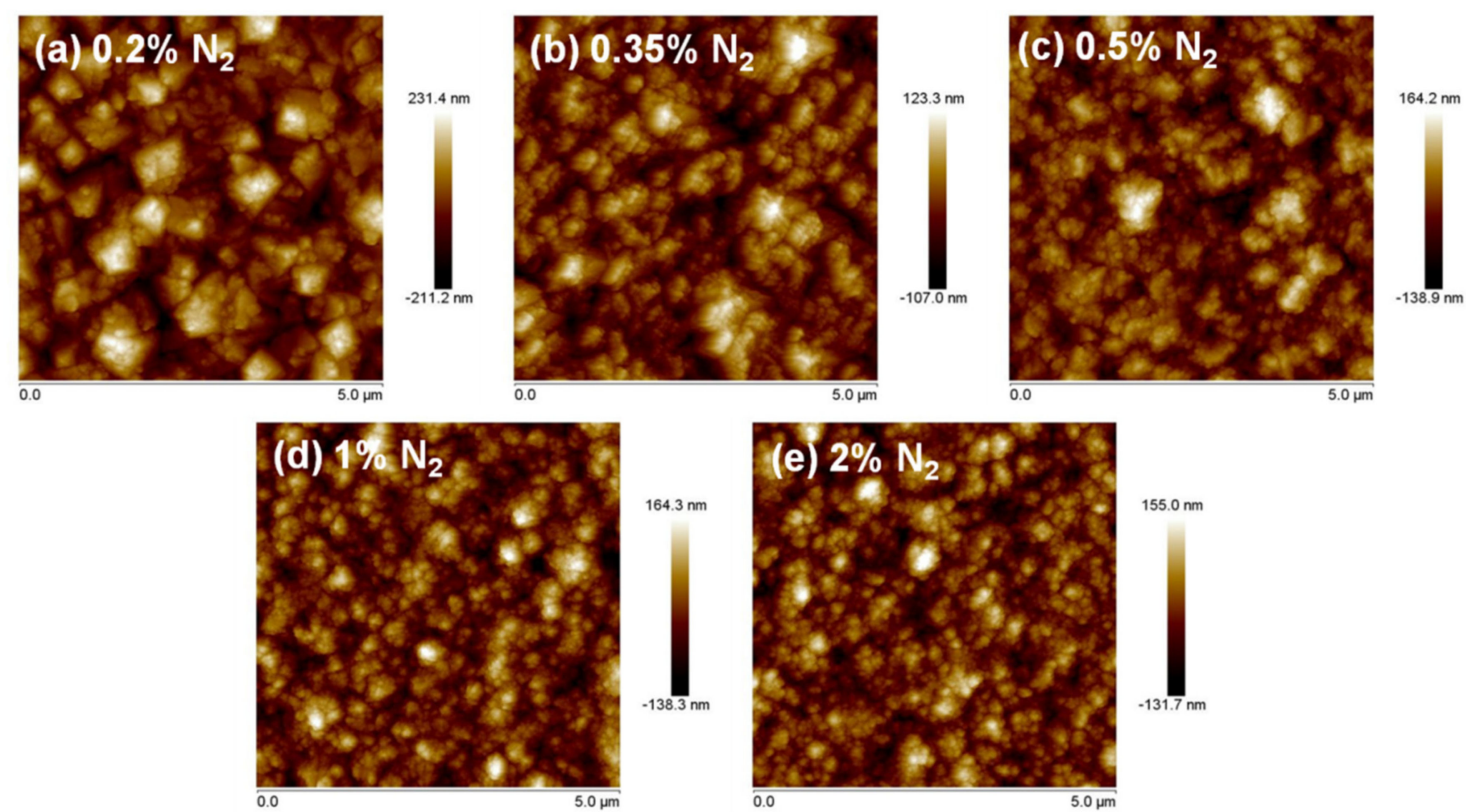

Figure 2. Topographic AFM images of the samples grown with (a) $0.2 \% \mathrm{~N}_{2}$, (b) $0.35 \% \mathrm{~N}_{2}$, (c) $0.5 \% \mathrm{~N}_{2}$, (d) $1 \% \mathrm{~N}_{2}$ and (e) $2 \% \mathrm{~N}_{2}$.

Figure 3 shows the Raman spectra of these samples. This technique allowed the evaluation of the crystalline quality of the NCD layer by exploring the bonding character of the carbon phases present in the samples. The two peaks located at about $\sim 1350 \mathrm{~cm}^{-1}$ (D-band) and $\sim 1580 \mathrm{~cm}^{-1}$ (G-band) are characteristic of carbon materials, and correspond to breathing and stretching modes in $\mathrm{sp}^{2}$-bonded 
carbon clusters, respectively [14,15]. Moreover, a third characteristic peak (labeled "dia") at $1332 \mathrm{~cm}^{-1}$ was observed that relates to $\mathrm{sp}^{3}$ diamond bonds. This peak looked sharp due to the microcrystalline character of the diamond film and ensured the diamond phase of the deposited film. The sharpness of the "dia" peak was related to defects and/or stress in the diamond phase and could be estimated by its FWHM. After Lorentz deconvolution, results of $14.0 \pm 0.5,15.7 \pm 0.7,12.8 \pm 0.8,20.3 \pm 1.0$, and $16.2 \pm 1.4 \mathrm{~cm}^{-1}$ were obtained for $0.2 \%, 0.35 \%, 0.5 \%, 1 \%$, and $2 \%$ nitrogen, respectively. There was no straightforward correlation between the FWHM and the nitrogen content. Consequently, there was no evidence of any effect on the stress or crystalline quality due to the addition of nitrogen to the gas mixture during growth. Nevertheless, this peak reveals that the diamond phase remained in all samples.

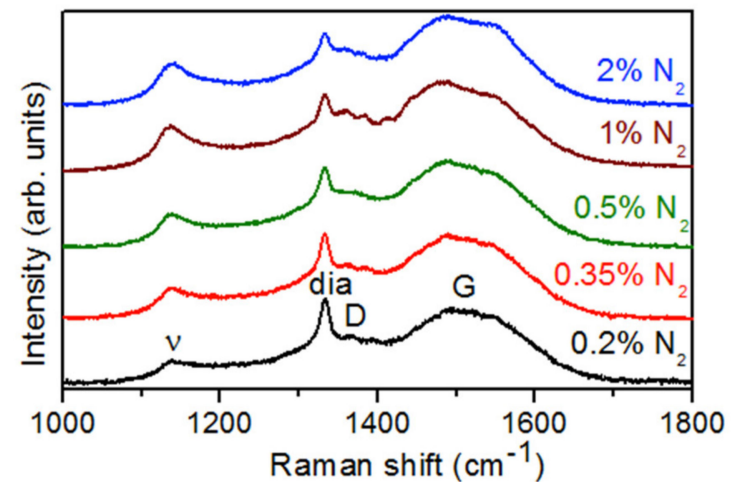

(a)

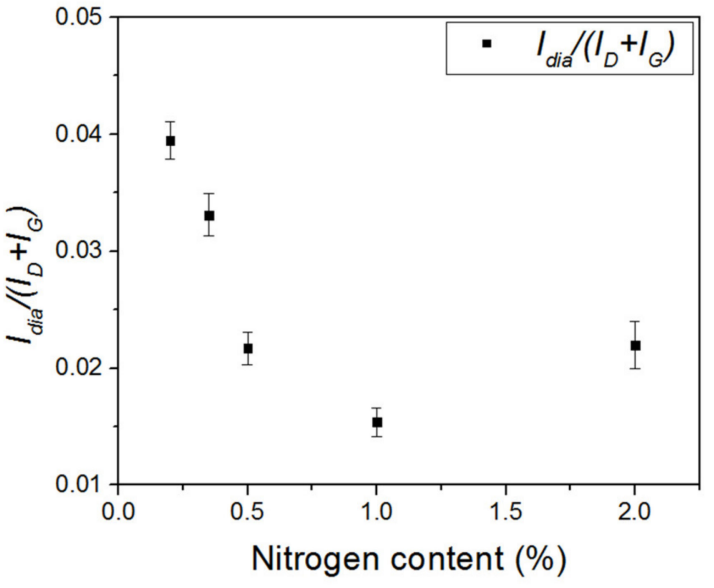

(b)

Figure 3. (a) Raman spectra of the NCD samples grown with different $\mathrm{N}_{2}$ concentrations. (b) Dia and $\mathrm{G}+\mathrm{D}$ bands ratio $\left(I_{\text {dia }} /\left(I_{\mathrm{D}}+I_{\mathrm{G}}\right)\right)$ for each nitrogen content.

A fourth peak appeared in the $v$ band at $\sim 1140 \mathrm{~cm}^{-1}$, which is the specific mode corresponding to trans-polyacetylene ( $t$-PA) segments and the vibration of $\mathrm{sp}^{2}$ carbon atoms bonded at the grain boundaries [16]. A second $v$ band was at $\sim 1460 \mathrm{~cm}^{-1}$ and overlapped the $G$ band. Raman spectra showed the increase of the $v$ band with $\mathrm{N}_{2}$ concentration, which resulted in the formation of nanosized diamond grains (in concordance with SEM micrographs (cf. Figure 1) and, consequently, more $\mathrm{sp}^{2}$ carbon bonded grain boundaries [8].

The $\mathrm{sp}^{2} / \mathrm{sp}^{3}$ ratio was estimated by the comparison of "dia", D, and G bands using the $I_{d i a} /\left(I_{\mathrm{D}}+I_{\mathrm{G}}\right)$ ratio. Figure $3 \mathrm{~b}$ shows this ratio, after deconvolution, as a function of the nitrogen concentration. There was an increase of the $\mathrm{sp}^{2}$ phases with the increase of nitrogen in the gas phase that tended to stabilize at $1 \%$.

The microstructure of the NCD samples was examined using TEM. Figure 4a shows a bright field (BF) TEM micrograph of the $0.2 \% \mathrm{~N}_{2}$ NCD sample. The selected area electron diffraction (SAED) pattern of an area $1 \mu \mathrm{m}$ in diameter is shown as an inset of Figure $4 \mathrm{a}$. Bigger grains that were hundreds of nanometers in size are evidenced, one of which is shown in the dark field (DF) mode in Figure $4 \mathrm{~b}$. The sample grown with $2 \%$ nitrogen is shown in BF mode in Figure 5a. The smaller grains required higher magnification. SAED was performed in the area with an aperture of $200 \mathrm{~nm}$ diameter (Figure 5b). Three different reflections in DF mode are provided in Figure $5 \mathrm{c}-\mathrm{e}$ to show the grains that were tens of nanometers in size. 

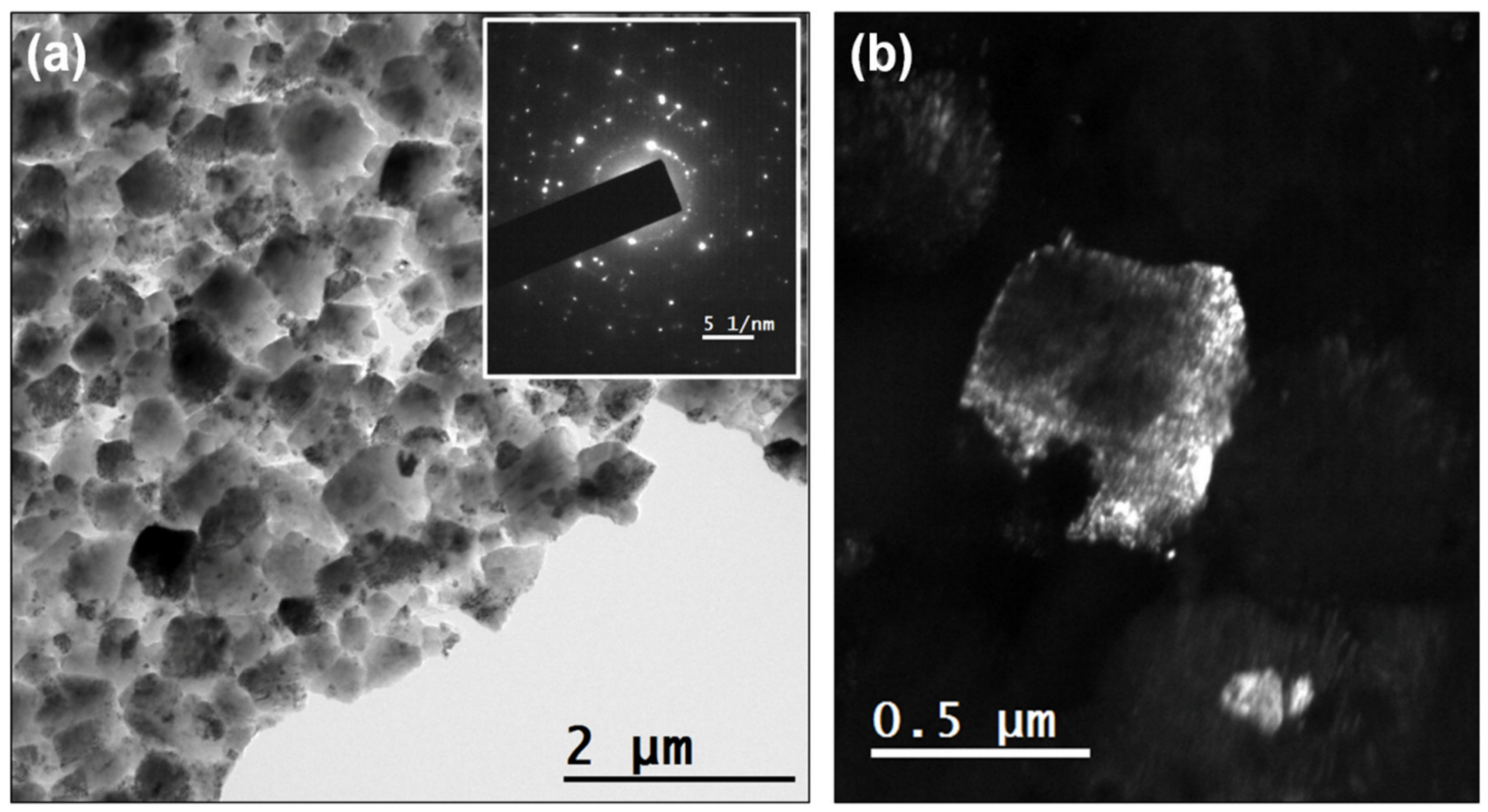

Figure 4. (a) Bright field (BF) TEM micrograph of sample grown with $0.2 \% \mathrm{~N}_{2}$. The inset of (a) shows the SAED pattern using an aperture with $1 \mu \mathrm{m}$ diameter. (b) Dark field (DF) micrograph of one reflection that shows one of the grains with good contrast.
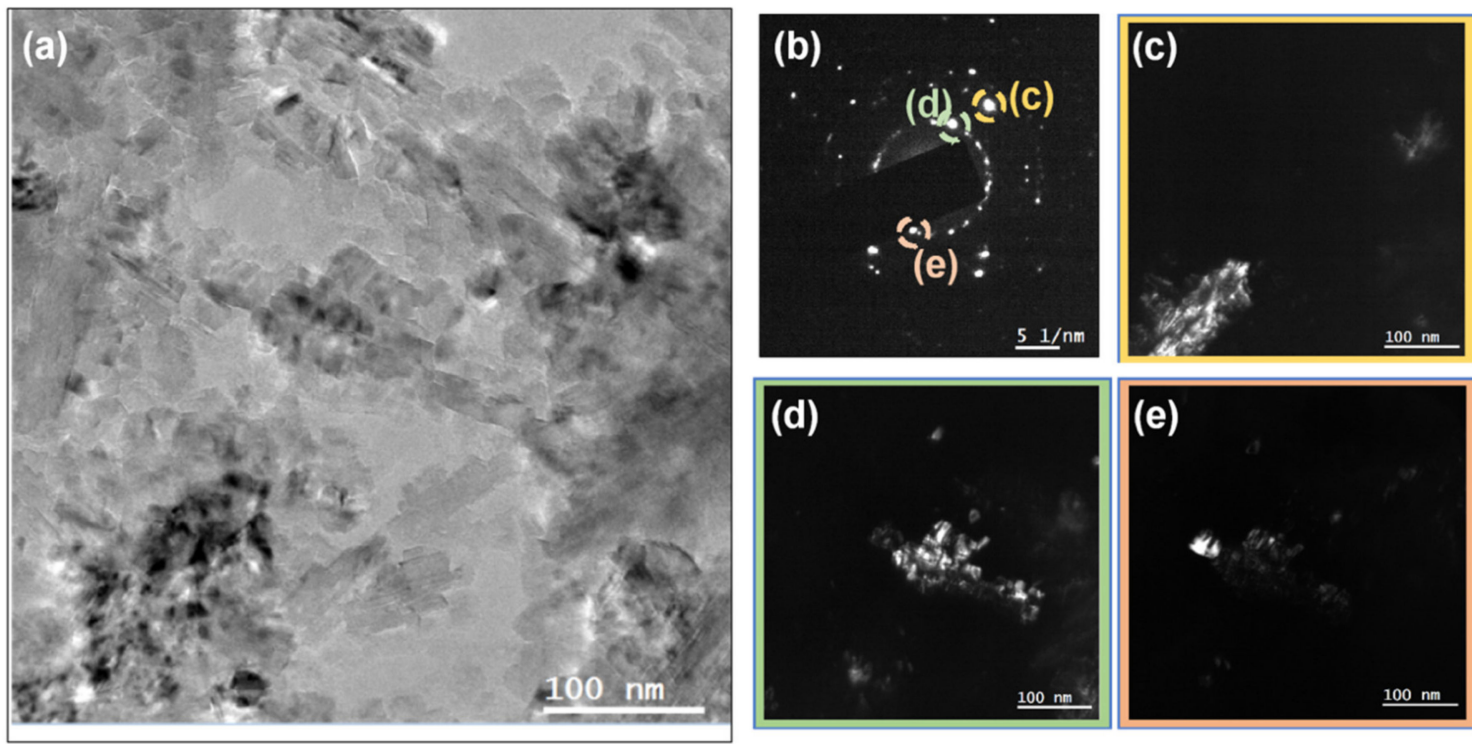

Figure 5. (a) BF TEM micrograph of the sample grown with $2 \% \mathrm{~N}_{2}$. (b) SAED pattern of the region shown in (a) using an aperture with $200 \mathrm{~nm}$ diameter. (c-e) DF micrographs of the reflections marked on the SAED pattern.

Figure 6a shows the FEE current density $(J)$ versus applied field $(E)$ of all co-doped NCD samples. The FEE results were Fowler-Nordheim $(\mathrm{FN})$ modeled [8], from which the turn-on field $\left(E_{0}\right)$ was determined for each film, as shown in Figure 6b. These values, summarized in Table 2, show a drastic reduction of $E_{0}$ for higher $\mathrm{N}_{2}$ content combined with a big increase in the current density. In this way, for the $0.2 \% \mathrm{~N}_{2}$ sample, the turn-on field was $83.7 \mathrm{~V} / \mu \mathrm{m}$, and the current density at $53 \mathrm{~V} / \mu \mathrm{m}$ applied field was $10^{-5} \mathrm{~mA} / \mathrm{cm}^{2}$, respectively. Similar values were obtained for $0.35 \% \mathrm{~N}_{2}\left(E_{0}=88.5 \mathrm{~V} / \mu \mathrm{m}\right.$ and $J=10^{-5} \mathrm{~mA} / \mathrm{cm}^{2}$ ) even if the SEM micrographs showed clear differences in the grain morphology between the $0.2 \% \mathrm{~N}_{2}$ and $0.35 \% \mathrm{~N}_{2} \mathrm{NCD}$ samples (cf. Figure 1). Nevertheless, at an $\mathrm{N}_{2}$ ratio of $0.5 \%$, the electric field for which the film can be turned on was reduced to half (i.e., $E_{0}=41.0 \mathrm{~V} / \mu \mathrm{m}$ ), while 
the current density increased to $J=22 \times 10^{-5} \mathrm{~mA} / \mathrm{cm}^{2}$. Interestingly, for the $2 \% \mathrm{~N}_{2}$ sample, $E_{0}$ reached its minimum value of $18.7 \mathrm{~V} / \mu \mathrm{m}$, with the current density reaching $13 \times 10^{-2} \mathrm{~mA} / \mathrm{cm}^{2}$. Moreover, the $\beta$ values were estimated from the slope $(m)$ of FN plots (see the arrow in Figure $6 \mathrm{~b}$ ) using the relation

$$
\beta=\left[-6.8 \times 10^{3} \varphi^{3 / 2}\right] / m
$$

where $\varphi$ is the work function, and $m$ is the slope of the FN plot. The calculated $\beta$ values were 27, $12,130,89$, and 230 for $0.2 \%, 0.35 \%, 0.5 \%, 1 \%$, and $2 \% \mathrm{~N}_{2}$ content, by taking the $\varphi$ value as $5.0 \mathrm{eV}$, respectively [17]. The nanosized diamond grains with wider grain boundaries in the $2 \% \mathrm{~N}_{2} \mathrm{NCD}$ sample were the main factors for the larger $\beta$ value. Consequently, the $2 \% \mathrm{~N}_{2}$ sample showed better FEE characteristics, viz. lower $E_{0}$ value, higher $J$ value, and larger $\beta$ values as compared with the other co-doped samples in this study.
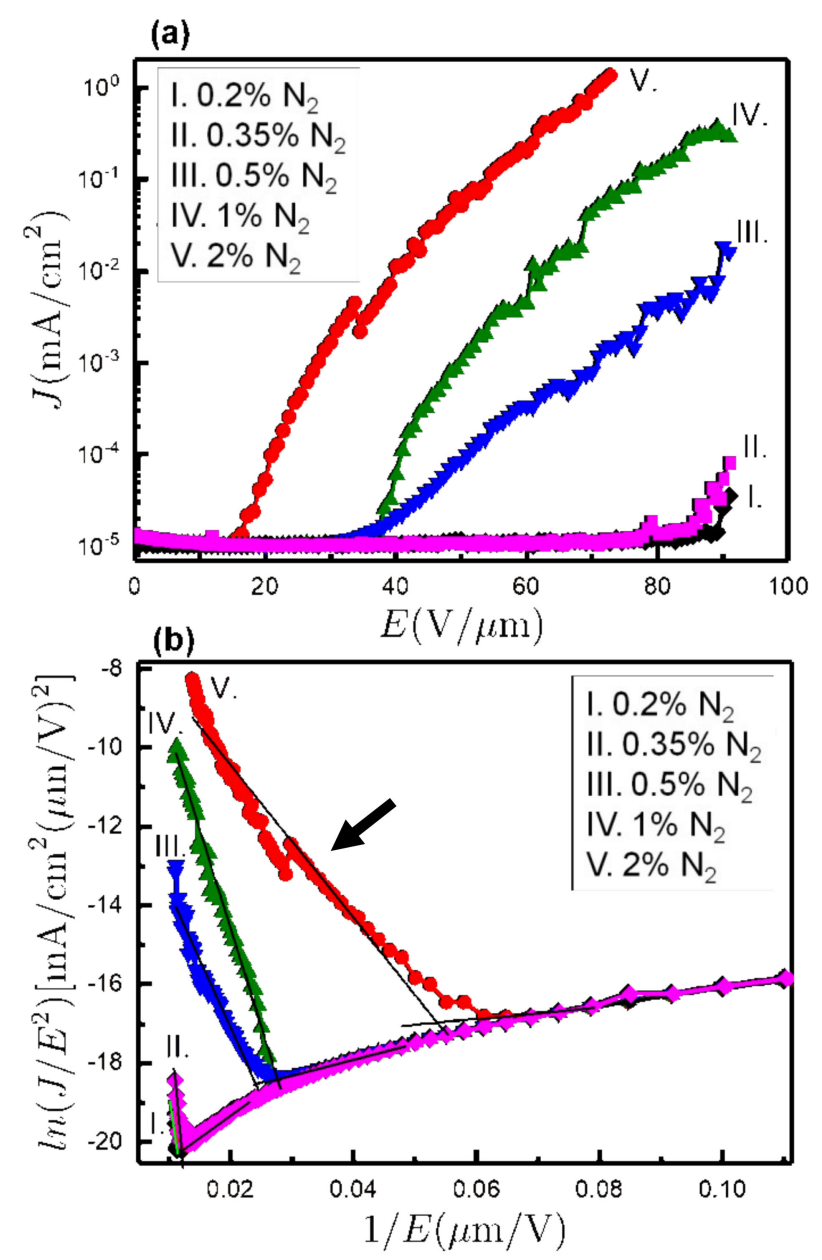

Figure 6. (a) FEE current density $(J)$ as a function of applied field $(E)$. (b) Fowler-Nordheim (FN) plots of the corresponding $J-E$ characteristic curves. All the results are shown for the five samples grown at different $\mathrm{N}_{2}$ contents. 
Table 2. Field electron emission (FEE) properties of $\mathrm{P}$ and $\mathrm{N}$ co-doped NCD films with varying $\mathrm{N}_{2}$ concentrations.

\begin{tabular}{cccc}
\hline $\mathbf{N}_{\mathbf{2}}$ & $\boldsymbol{E}_{\mathbf{0}}(\mathrm{V} / \boldsymbol{\mu \mathrm { m }})$ & $\boldsymbol{\beta}$ & $\boldsymbol{J}$ at $\mathbf{5 3} \mathrm{V} / \boldsymbol{\mu m}$ \\
\hline $0.2 \%$ & 83.7 & 27 & $1 \times 10^{-5}\left(\mathrm{~mA} / \mathrm{cm}^{2}\right)$ \\
$0.35 \%$ & 88.5 & 12 & $1 \times 10^{-5}\left(\mathrm{~mA} / \mathrm{cm}^{2}\right)$ \\
$0.5 \%$ & 41.0 & 130 & $22 \times 10^{-5}\left(\mathrm{~mA} / \mathrm{cm}^{2}\right)$ \\
$1 \%$ & 36.2 & 89 & $26 \times 10^{-4}\left(\mathrm{~mA} / \mathrm{cm}^{2}\right)$ \\
$2 \%$ & 18.7 & 230 & $13 \times 10^{-2}\left(\mathrm{~mA} / \mathrm{cm}^{2}\right)$ \\
\hline
\end{tabular}

To determine the reason for the enhancement of the FEE characteristics of the $2 \% \mathrm{~N}_{2} \mathrm{NCD}$ sample, C-AFM measurements were carried out to detect the current conduction paths of the NCD films. Figure $7 \mathrm{a}, \mathrm{c}$ shows the C-AFM topographic image and the corresponding current signal for $2 \% \mathrm{~N}_{2} \mathrm{NCD}$. C-AFM measurements of the $0.2 \% \mathrm{~N}_{2}$ NCD sample were also carried out for comparison (Figure $7 \mathrm{~b}, \mathrm{~d}$ ). The brighter contrast in the current images signifies a larger emission current. For both samples, larger emission current was observed from the grain boundaries, which was due to the presence of $\mathrm{sp}^{2}$-bonded carbon phases at the grain boundaries confirmed from the Raman results (Figure 3). Harniman et al. [18] also observed that FEE from diamond surfaces originates preferentially from the grain boundaries and not from other topographical features. This was observed in low-doping samples where grain boundaries remained relatively conductive compared to the bulk grains. In these samples, the electrons used the grain boundaries as a path to climb from the base of the film to the surface, where they were emitted. The situation changed when the grains were conductive, causing some of the current to be transported through the grains themselves and be emitted from the facets. In our results, the number density of highly conductive regions was larger for $2 \% \mathrm{~N}_{2} \mathrm{NCD}$ than that of $0.2 \% \mathrm{~N}_{2} \mathrm{NCD}$ because $2 \% \mathrm{~N}_{2} \mathrm{NCD}$ films contained more $\mathrm{sp}^{2}$-bonded phases at the grain boundaries, which was in accordance with the Raman studies. Moreover, emission sites were also observed from the P-doped diamond grains of $2 \% \mathrm{~N}_{2} \mathrm{NCD}$. Hence the C-AFM measurements clearly illustrate the existence of a high density of local electron emission sites in $2 \% \mathrm{~N}_{2} \mathrm{NCD}$, implying the formation of conductive nanochannels at the grains and grain boundaries resulting in the enhanced FEE properties [19]. In our previous studies, it was observed that phosphorus was doped directly inside the lattice of the diamond [11], which made the diamond grains conductive. However, the main factor responsible for the reduction of nanosized diamond grains and the induction of $\mathrm{sp}^{2}$-bonded carbon phases in the grain boundaries is still not clear.

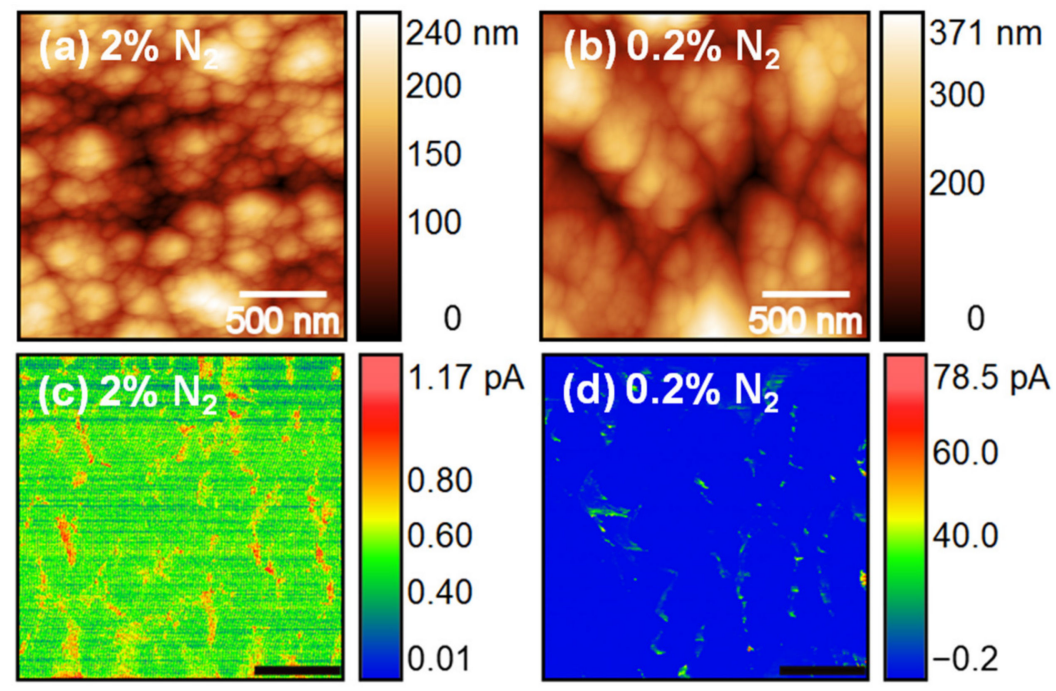

Figure 7. C-AFM topographic images (a,b) and the corresponding current signal (c,d) of $2 \% \mathrm{~N}_{2}$ NCD and $0.2 \% \mathrm{~N}_{2}$ NCD samples, respectively. 
To determine the factors responsible, we carried out in situ OES measurements during the sample growth. Figure 8a shows optical emission spectra taken from the plasma during NCD sample growth from $\mathrm{CH}_{4} / \mathrm{H}_{2} / \mathrm{N}_{2} / \mathrm{PH}_{3}$ gas mixtures with varying $\mathrm{N}_{2}$ concentrations. The $\mathrm{H}_{\alpha}$ and $\mathrm{H}_{\beta}$ lines are the Balmer atomic hydrogen emission lines observed at $\sim 655$ and $\sim 484 \mathrm{~nm}[20,21]$, respectively, whereas the $\mathrm{CN}$ violet system (386.3 and $418.1 \mathrm{~nm}$ ) and the $\mathrm{N}_{2}$ line at $357.3 \mathrm{~nm}$ [22] were induced due to the addition of $\mathrm{N}_{2}$. The intensity of $\mathrm{CN}$ and $\mathrm{N}_{2}$ lines increased as the $\mathrm{N}_{2}$ concentration in the plasma increased, and reached a maximum for $2 \% \mathrm{~N}_{2} \mathrm{NCD}$ (Figure 8, spectrum V). Generally, the $\mathrm{CH}_{4}$ species in the plasma dissociated and formed $\mathrm{CH}_{\mathrm{x}}$ species $(\mathrm{x}=1,2,3)$. However, the $\mathrm{CH}$ lines were overlapped by the $\mathrm{CN}$ line $[23,24]$, and lines at 386.3 and $418.1 \mathrm{~nm}$ were marked as $\mathrm{CN}$ $+\mathrm{CH}$. The $\mathrm{C}_{2}$ swan system at $516.0 \mathrm{~nm}$ was also observed with low intensity [25]. Our previous studies stated that the presence of $\mathrm{CH}$ and $\mathrm{C}_{2}$ species are responsible for the origin of nanosized diamond grains because the $\mathrm{C}_{2}$ species re-nucleate diamond easily, whereas the $\mathrm{CH}$ species passivate the diamond nuclei and efficiently result in the formation of nanosized diamond grains [10,25]. Based on the recorded spectra, Figure $8 \mathrm{~b}$ shows a comparative graph of the species in the plasma during the growth. At a high concentration of $\mathrm{N}_{2}(2 \%)$ in the plasma, the $\mathrm{CN}+\mathrm{CH}$ peaks increased. This was probably due to an increase of the $\mathrm{CN}$ species that were more present as compared to the $\mathrm{CH}$ species [8]. Moreover, the NCD films were grown at a high growth temperature $\left(>700{ }^{\circ} \mathrm{C}\right)$, which made it energetically favorable for the $\mathrm{CN}$ species to be more active, likely resulting in the formation of $\mathrm{sp}^{2}$-bonded carbon at the grain boundaries $[10,26]$. Hence $\mathrm{CN}, \mathrm{CH}$, and $\mathrm{C}_{2}$ species were the main factors for the origin of the nanosized diamond grains and the induction of $\mathrm{sp}^{2}$-bonded carbon phases in the grain boundaries of $2 \% \mathrm{~N}_{2}$ NCD films.
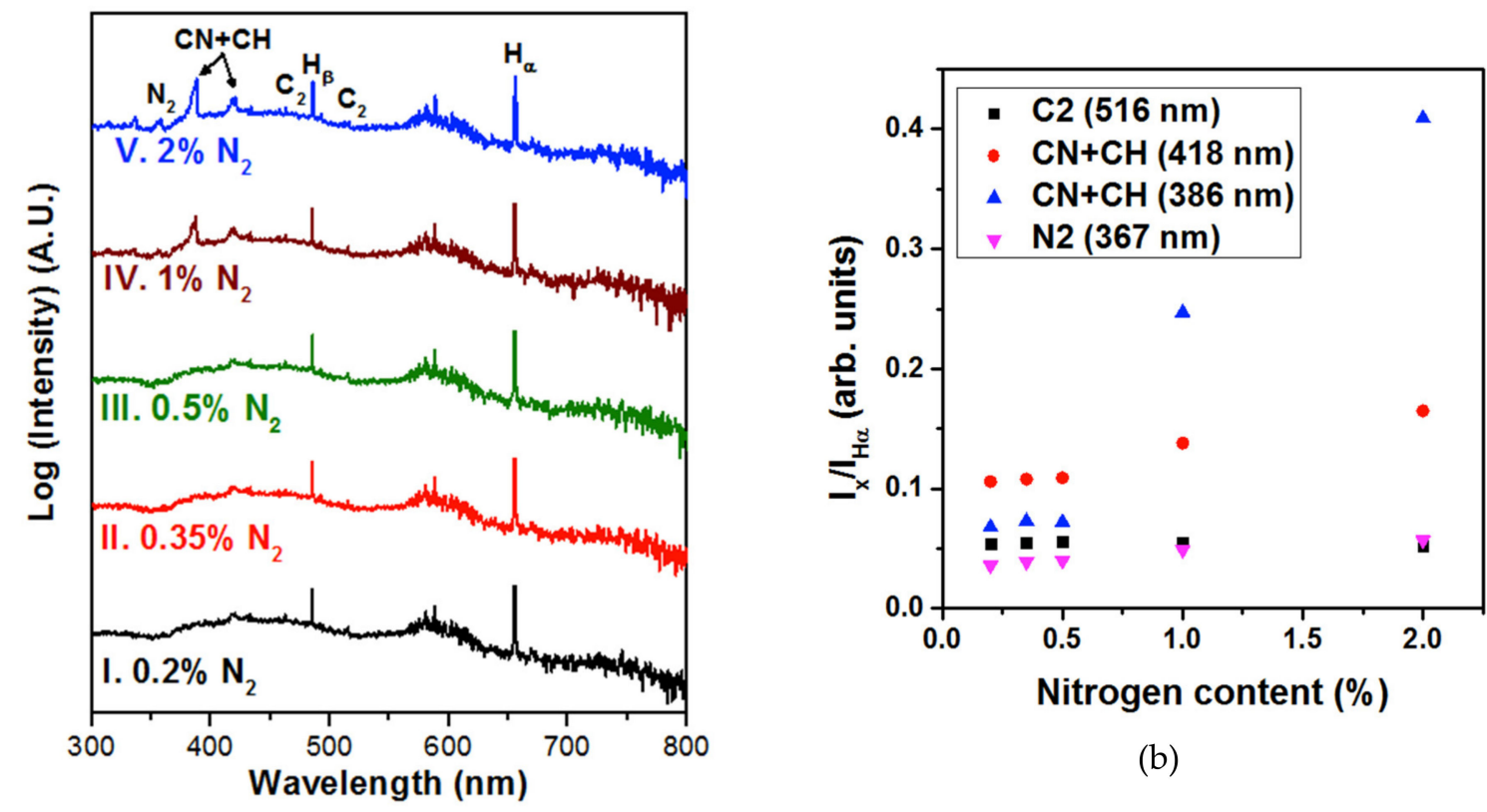

(b)

(a)

Figure 8. (a) OES spectra recorded during the deposition process of the five samples labelled by their $\mathrm{N}_{2}$ amount. (b) Intensity of $\mathrm{C}_{2}, \mathrm{~N}_{2}$, and $\mathrm{CN}+\mathrm{CH}$ peaks normalized to the $\mathrm{H}_{\alpha}$ peak for each nitrogen content used.

\section{Conclusions}

From this study, the combined effect of $\mathrm{PH}_{3}$ and $\mathrm{N}_{2}$ on the drastic reduction of diamond grain size and the consequent enlarging of the grain boundaries was clearly evidenced. Roughness reduction was illustrated by AFM, while the reduction of grain size was pointed out by SEM and TEM. C-AFM studies showed that more emission sites from diamond grains and $\mathrm{sp}^{2}$-bonded carbon grain boundaries of an NCD sample co-doped with $\mathrm{P}$ and $\mathrm{N}$, with $2 \% \mathrm{~N}_{2}$ used in the gas phase, resulting in enhanced FEE 
properties, viz. a low $E_{0}$ value of $18.7 \mathrm{~V} / \mu \mathrm{m}$, a high current density of $13 \times 10^{-2} \mathrm{~mA} / \mathrm{cm}^{2}$, and a field enhancement factor of 230 . The $\mathrm{CN}, \mathrm{CH}$, and $\mathrm{C}_{2}$ species in the growth plasma were considered the prime factors for the origin of the nanosized diamond grains and the induction of $\mathrm{sp}^{2}$-bonded carbon phases in the grain boundaries of the co-doped NCD films.

Author Contributions: Conceptualization, K.J.S. and F.L.; methodology, K.J.S. and F.L.; validation, K.H., M.G., and H.-G.B.; formal analysis, K.J.S.; investigation, F.L., J.M.-B., D.D., R.R., and P.P.; writing-original draft preparation, F.L.; writing-review and editing, K.J.S. All authors have read and agreed to the published version of the manuscript.

Funding: The authors appreciate the financial support of the Research Foundation - Flanders (FWO) via Research Project G0D4920N, SBO Project S004018N, and the Methusalem "NANO" network, as well as the co-financing by the 2014-2020 ERDF Operational Programme and by the Department of Economy, Knowledge, Business and University of the Regional Government of Andalusia. Project reference: FEDER-UCA18-107851. P.P. is a Postdoctoral Fellow of the Research Foundation - Flanders (FWO). We also thank to the Ministerio de Economía y Empresa (MINECO) Spanish Government for funding under grant N ${ }^{\circ}$ TEC2017-86347-C2-1-R and Nº ESP2017-91820-EXP.

Conflicts of Interest: The authors declare no conflicts of interest. The funders had no role in the design of the study; in the collection, analyses, or interpretation of data; in the writing of the manuscript; or in the decision to publish the results.

\section{References}

1. Balmer, R.S.; Brandon, J.R.; Clewes, S.L.; Dhillon, H.K.; Dodson, J.M.; Friel, I.; Inglis, P.N.; Madgwick, T.D.; Markham, M.L.; Mollart, T.P.; et al. Chemical vapour deposition synthetic diamond: Materials, technology and applications. J. Phys. Condens. Matter 2009, 21, 364221.

2. Sankaran, K.J.; Srinivasu, K.; Leou, K.C.; Tai, N.H.; Lin, I.N. High stability electron field emitters made of nanocrystalline diamond coated carbon nanotubes. Appl. Phys. Lett. 2013, 103, 251601.

3. Terranova, M.L.; Orlanducci, S.; Rossi, M.; Tamburri, E. Nanodiamonds for field emission: State of the art. Nanoscale 2015, 7, 5094-5114.

4. Sankaran, K.J.; Joseph, P.T.; Chen, H.C.; Tai, N.H.; Lin, I.N. Investigation in the role of hydrogen on the properties of diamond films grown using $\mathrm{Ar} / \mathrm{H}_{2} / \mathrm{CH}_{4}$ microwave plasma. Diam. Relat. Mater. 2011, 20, 232.

5. Arenal, R.; Bruno, P.; Miller, D.J.; Bleuel, M.; Lal, J.; Gruen, D.M. Diamond nanowires and the insulator-metal transition in ultrananocrystalline diamond films. Phys. Rev. B 2007, 75, 195431.

6. Cuenca, J.A.; Sankaran, K.J.; Pobedinskas, P.; Panda, K.; Lin, I.N.; Porch, A.; Haenen, K.; Williams, O.A. Microwave cavity perturbation of nitrogen doped nano-crystalline diamond films. Carbon 2019, 145, 740.

7. Bhattacharyya, S.; Auciello, O.; Birrell, J.; Carlisle, J.A.; Curtiss, L.A.; Goyette, A.N.; Gruen, D.M.; Krauss, A.R.; Schlueter, J.; Sumant, A.; et al. Synthesis ad characterization of highly-conducting nitrogen doped ultrananocrystalline diamond films. Appl. Phys. Lett. 2001, 79, 1441.

8. Sankaran, K.J.; Tai, N.H.; Lin, I.N. Microstructural evolution of diamond films from $\mathrm{CH}_{4} / \mathrm{H}_{2} / \mathrm{N}_{2}$ plasma and their enhanced electrical properties. J. Appl. Phys. 2015, 117, 075303.

9. Pradhan, D.; Lin, I.N. Grain-size-dependent diamond-nondiamond composite films: Characterization and field-emission properties. ACS Appl. Mater. Interfaces 2009, 1, 1444-1450.

10. Sankaran, K.J.; Yeh, C.J.; Hsieh, P.Y.; Pobedinskas, P.; Kunuku, S.; Leou, K.C.; Tai, N.H.; Lin, I.N.; Haenen, K. Origin of conductive nanocrystalline diamond nanoneedles for optoelectronic applications. ACS Appl. Mater. Interfaces 2019, 11, 25388-25398.

11. Janssen, W.; Turner, S.; Sakr, G.; Jomard, F.; Barjon, J.; Degutis, G.; Lu, Y.G.; D’Haen, J.; Hardy, A.; Van Bael, M.; et al. Substitutional phosphorus incorporation in nanocrystalline CVD diamond thin films. Phys. Status Solidi RRL 2014, 8, 705-709.

12. Haenen, K.; Lazea, A.; Barjon, J.; D’Haen, J.; Habka, N.; Teraji, T.; Koizumi, S.; Mortet, V. P-doped diamond grown on (110)-textured microcrystalline diamond: Growth, characterisation and devices. J. Phys. Condens. Matter 2009, 21, 364204.

13. Williams, O.A.; Douheret, O.; Daenen, M.; Haenen, K.; Osawa, E.; Takahashi, M. Enhanced diamond nucleation on monodispersed nanocrystalline diamond. Chem. Phys. Lett. 2007, 445, 255.

14. Wu, Z.S.; Pei, S.; Ren, W.; Tang, D.; Gao, L.; Liu, B.; Li, F.; Cheng, H.M. Field emission of single-layer graphene films prepared by electrophoretic deposition. Adv. Mater. 2009, 21, 1756. 
15. Birrell, J.; Gerbi, J.E.; Auciello, O.; Gibson, J.M.; Johnson, J.; Carlisle, J.A. Interpretation of the Raman spectra of ultrananocrystalline diamond. Diam. Relat. Mater. 2005, 14, 86.

16. Xiao, X.; Birrell, J.; Gerbi, J.E.; Auciello, O.; Carlisle, J.A. Low temperature growth of ultrananocrystalline diamond. J. Appl. Phys. 2004, 96, 2232.

17. Liu, J.; Zhirnov, V.V.; Myers, A.F.; Wojak, G.J.; Choi, W.B.; Hren, J.J.; Wolter, S.D.; McClure, M.T.; Stoner, B.R.; Glass, J.T. Field emission characteristics of diamond coated silicon field emitters. J. Vac. Sci. Technol. B 1995, 13, 422-426.

18. Harniman, R.L.; Fox, O.J.; Janssen, W.; Drijkoningen, S.; Haenen, K.; May, P.W. Direct observation of electron emission from grain boundaries in CVD diamond by PeakForce-controlled tunnelling atomic force microscopy. Carbon 2015, 94, 386-395.

19. Deshmukh, S.; Sankaran, K.J.; Srinivasu, K.; Korneychuk, S.; Banerjee, D.; Barman, A.; Bhattacharya, G.; Phase, D.M.; Gupta, M.; Verbeeck, J.; et al. Local probing of the enhanced field electron emission of vertically aligned nitrogen-doped diamond nanorods and their plasma illumination properties. Diam. Relat. Mater. 2018, 83, 118-125.

20. Marcus, B.; Mermoux, M.; Vinet, F.; Campargue, A.; Chenevier, M. Relationship between emission spectroscopy and structural properties of diamond films synthesized by plasma-assisted chemical vapor deposition. Surf. Coat. Technol. 1991, 47, 608-617.

21. Shigesato, Y.; Boekenhauer, R.E.; Sheldon, B.W. Emission spectroscopy during direct-current-biased, microwave-plasma chemical vapor deposition of diamond. Appl. Phys. Lett. 1993, 63, 314-316.

22. Balestrino, G.; Marinelli, M.; Milani, E.; Paoletti, A.; Paroli, P.; Pinter, I.; Tebano, A. Systematic investigation of plasma emission spectra during microwave diamond deposition from $\mathrm{CH}_{4}-\mathrm{CO}_{2}$ and $\mathrm{C}_{2} \mathrm{H}_{2}-\mathrm{CO}_{2}$ gas mixtures. Diam. Relat. Mater. 1993, 2, 389-392.

23. May, P.W.; Mankelevich, Y.A. From ultrananocrystalline diamond to single crystal diamond growth in hot filament and microwave plasma-enhanced cvd reactors: A unified model for growth rates and grain sizes. J. Phys. Chem. C 2008, 112, 12432-12441.

24. Vandevelde, T.; Wu, T.D.; Quaeyhaegens, C.; Vlekken, J.; D'Olieslaeger, M.; Stals, L. Correlation between the OES plasma composition and the diamond properties during microwave PA-CVD with nitrogen addition. Thin Solid Films 1999, 340, 159-163.

25. Eckert, M.; Neyts, E.; Bogaerts, A. Differences between ultrananocrystalline and nanocrystalline diamond growth: Theoretical investigation of $\mathrm{CxHy}$ species at diamond step Edges. Crys. Growth Des. 2010, 10, 4123-4134.

26. Sankaran, K.J.; Kurian, J.; Chen, H.C.; Dong, C.L.; Lee, C.Y.; Tai, N.H.; Lin, I.N. Origin of a needle-like granular structure for ultrananocrystalline diamond films frown in a $\mathrm{N}_{2} / \mathrm{CH}_{4}$ plasma. J. Phys. D Appl. Phys. 2012, 45, 365303.

(C) 2020 by the authors. Licensee MDPI, Basel, Switzerland. This article is an open access article distributed under the terms and conditions of the Creative Commons Attribution (CC BY) license (http://creativecommons.org/licenses/by/4.0/). 